\title{
Mulheres e poder. Histórias, ideias e indicadores
}

Lectura crítica de Hildete Pereira de Melo y Débora Thomé (2018)

Río de Janeiro, FGV Editora, 190 pp.

\section{Joaquina Altamirano}

Universidad Católica de La Plata

¿Es posible sistematizar el conocimiento feminista? ¿Está dentro de nuestras posibilidades intentar mostrar las obras y acciones de las mujeres a lo largo de la historia? Hildete Pereira de Melo y Débora Thomé, feministas brasileras, proponen en ciento noventa páginas un océano de conocimiento de un centímetro de profundidad, que intenta responder estos interrogantes.

El libro es una excelente forma de adentrarse en el feminismo para quienes no lo han hecho todavía, y es aún más interesante para indagar sobre la historia y la realidad brasileras. Las autoras describen de un modo sucinto debates y temas comunes a toda cuestión social, al feminismo, a Brasil y a las realidades mundiales y latinoamericanas. De este modo, aparecen interconectados numerosos disparadores de reflexiones y futuras investigaciones.

Lo que el libro propone en definitiva es una estrategia dual: un llamado a la acción en la actividad académica, buscando ampliar los conocimientos sobre el feminismo y las mujeres, que se combine con una actividad práctica, para actuar como grupos de presión en los ámbitos sociales, económicos y sobre todo políticos. Esta proposición está emparentada con las trayectorias personales de ambas. Pereira de Melo empezó sus pasos en la academia desde la economía y se encontró con las luchas de las mujeres en la década de los 70, participó activamente desde entonces hasta la actualidad y tuvo cargos durante los gobiernos del Partido dos Trabalhadores (PT) en el área de género.

Por su parte, Débora Thomé es politóloga y periodista y, además de ser activista por los derechos de las mujeres, fue mentora de más de trescientas mujeres candidatas en 2016 en un programa financiado por la Secretaria de Políticas para as Mulheres.
La mayor virtud de la obra tal vez sea su principal debilidad: la brevedad. La cantidad de tópicos abordados genera muchas veces la sensación de ser tratados de manera superficial. Ahora bien, las autoras dejan expreso que la pretensión de la obra no es otra que la de generar un estado del arte del curso de las discusiones sobre las mujeres y el poder en Brasil y en el mundo, recalcando que su intención es ofrecer información lo más variada posible. Por ello, debemos decir que, en este sentido, el objetivo está más que cumplido.

El libro se estructura en ocho capítulos con una introducción y una conclusión. En el comienzo, se hace referencia a las distintas corrientes teórico-prácticas del feminismo, continúa con un capítulo dedicado a la relación mujeres-historia para luego profundizar en el caso de la historia brasilera y el papel de las mujeres en ella. En el capítulo cuatro, abordan temas referidos a la demografía y en el cinco la importancia de la educación formal en la trayectoria de las mujeres, con especial hincapié en la situación de Brasil. El sexto capítulo versa sobre las feminidades en el mundo del trabajo, y el séptimo sobre la relación con el mundo de la política, para concluir en un capítulo dedicado a abordar las políticas públicas y legislación con sus cambios y continuidades a partir de la inclusión de las mujeres en la arena política, así como su incidencia en la vida de las mismas.

Las autoras comienzan incluyendo al feminismo dentro de los enfoques de la Ciencia Política, ya que su teoría versa sobre la distribución desigual del poder en las sociedades humanas, y su objeto principal es la percepción colectiva de la opresión de las mujeres. Ambas van a proponer a El Segundo Sexo de Simone de Beauvoir como el impulsor del feminismo del siglo $X X$. De este parten para entender que el concepto género es central, porque permite significar las relaciones de poder (De Beauvoir, 2016: 18-21, 267-268). El mismo aparece como categoría analítica novedosa 
y amplía los horizontes sobre sujetxs y objetxs de la lucha feminista (Scott, 1990; Butler, 2017).

En la obra, se abordan teorías y luchas como las de los feminismos liberal, radical, marxista, cultural, los feminismos negros e interseccionales. Sin embargo, muchas veces esta diversidad se deja de lado al definir como objetx/sujetx del feminismo a las mujeres. ¿A quiénes abarca el feminismo? ¿Quiénes son sus sujetxs? Son preguntas de la academia, porque en la práctica Ixs cuerpxs que participan en las luchas feministas trascienden la lógica binaria.

Pereira de Melo y Thomé retoman procesos históricos, para introducir una arista interesante de observación de las lógicas de opresión ya mencionadas: ellas entienden que las mujeres han sido sistemáticamente apagadas en la historia. Para estas autoras, los momentos revolucionarios de la Modernidad han sido focos de luz en el accionar histórico de las mujeres, porque el cuestionamiento del orden establecido trajo consigo la posibilidad de poner en duda los modelos patriarcales. Sin embargo, aquellas revoluciones que lograron introducir múltiples cambios en diversos aspectos de la vida política, económica y social, perpetraron la reproducción de lógicas patriarcales. De este modo, la Revolución Francesa, la Independencia Norteamericana, incluso la Revolución Rusa y la Mexicana son revisadas a partir de sus principales participantes individuales femeninas.

Para comenzar a hablar de la historia de Brasil, optan por hacer un corte temporal en el siglo XIX por la complejidad de hallar fuentes de períodos anteriores. Aun así, las autoras advierten que las particularidades de la opresión histórica de las mujeres brasileras provienen sobre todo de la cuestión colonial, cuando dicho país tuvo la particularidad de ser sustrato territorial de la metrópolis y la colonia en simultáneo.

En el siglo XIX, fueron mujeres blancas y escolarizadas las precursoras del feminismo en Brasil. Para las autoras, el acceso a la educación es un elemento clave en las luchas feministas, de hecho, dentro del desarrollo del feminismo en este país, las luchas por los derechos educativos y políticos fueron análogas, así como la abolición de la esclavitud fue un enclave de la resistencia de las mujeres negras. En este punto también apelan al uso de ejemplos individuales para relatar las luchas colectivas.

Dentro de estos relatos históricos, las autoras evidencian y concluyen que es un rasgo común a los diversos feminismos la ausencia de articulación con el Estado, lo que implica una paradoja: es el Estado, como principal articulador del sistema patriarcal, el que identificamos como objeto de nuestras críticas pero, al mismo tiempo, es uno de los canales de acción más importantes para modificar los patrones opresores de la vida en sociedad. Para revisar esta relación, las autoras indagan en la demografía, la educación y el trabajo como dimensiones verificables a través de los procesos históricos que evidencian la desigualdad de género.

Pereira de Melo y Thomé afirman que las mujeres son tratadas como una minoría aunque numéricamente no lo sean, y esto se debe a que son el grupo más vulnerable y con menos poder en las distintas sociedades. Aun así, indicadores demográficos como las tasas de natalidad, de mortalidad y de fecundidad están principalmente atravesados por las trayectorias de vida de las mujeres, lo que hace que los estudios sobre ellas sean de vital importancia para abordar aquellos sobre demografía. Incluso lo son para las Ciencias Sociales, por ejemplo las tasas de embarazo adolescente o de mortalidad materna como factores que aumentan la vulnerabilidad de las mujeres e implican repensar la relación sexualidad-reproducción, la desigualdad interseccional en los sistemas sanitarios, la mutación de los esquemas familiares y del rol social de las mujeres.

En el caso de la educación, las autoras marcan que es la dimensión más importante y que más evidencia la desigualdad. Las mujeres conforman la mayoría de lxs integrantes del sistema educativo y además aumenta su cantidad a medida que se sube en sus niveles. ${ }^{1} \mathrm{Al}$ mismo tiempo, el mundo científico sigue siendo un mundo masculino (y sobre todo blanco), lo que en parte permite entender la falta de sistematización del conocimiento sobre y de las mujeres. Según esta obra, el feminismo tiene como desafío resaltar a las que han trabajado invisiblemente en él y poner su trabajo al servicio de las luchas colectivas.

En el caso brasilero, la igualdad educativa fue una de las demandas primigenias del feminismo decimonónico que fue alcanzada en parte recién en la década de los años 90 del siglo XX, pero este proyecto queda inconcluso para las autoras, porque la cantidad de mujeres en el mundo educativo no tiene correlato en el mundo laboral.

1 Este punto debe leerse en clave interseccional, los índices no son iguales para todas, las mujeres negras e indígenas no tienen las mismas posibilidades que las blancas. Además, existen problemas específicos en la deserción de las mujeres del sistema educativo: el embarazo adolescente, la dedicación a tareas domésticas de crianza y/o cuidado, etc. 
El mercado de trabajo es sensible al rol tradicional de las mujeres, contratadas por los sectores que se encargan de tareas reproductivas y de cuidado, cuando los varones son mayoría en los sectores productores de bienes materiales. A pesar de los mayores niveles educativos alcanzados por las mujeres, los puestos jerárquicos son mayoritariamente androcéntricos y la desigualdad de pago es notable. Ambos fenómenos son, para las autoras, males generales que se dan en ámbitos públicos, privados, rurales y urbanos.

Un punto de partida que plantean las autoras para abordar el mundo del trabajo con perspectiva de género es el trabajo doméstico, que responde a una división sexual del trabajo vigente aún en el siglo XXI. El mandato imperativo de su realización por parte de la población femenina rige incluso para las mujeres profesionales. Aun cuando una mujer decide no ocuparse personalmente de las tareas reproductivas domésticas, son otras mujeres quienes la reemplazan con o sin salario. En Brasil, el primer y principal rubro de trabajo femenino es el empleo doméstico remunerado.

Este rubro laboral es la principal evidencia de las falencias que tienen las Ciencias Económicas para explicar los trabajos históricamente feminizados. Como factor general, las teorías económicas clásicas son indiferentes a la categorización por género del factor trabajo, y dentro de las mismas se asocia la falta de salario a la no productividad. De este modo, las mediciones tradicionales de los PBI nacionales no contemplan el trabajo doméstico. Sin embargo, son teóricas feministas quienes han presentado cálculos alternativos que sí lo hacen, $y$-en el caso brasileropermiten variar el $\mathrm{PBI}$ en once puntos.

Así como los varones se presentan como la mayoría y la norma en las áreas que mencionamos anteriormente, las autoras plantean que son ellos quienes detentan el monopolio de la representación política. A pesar del fundamental accionar de las mujeres latinoamericanas en los retornos a la democracia en los años 8o, y sus luchas políticas en todo el globo, la mejora de los índices en materia de igualdad de género no desmanteló los obstáculos para su acceso a la vida política institucional.

Partiendo de los escritos de Franceschet, Pereira de Melo y Thomé dividen en tres los tipos de representación: descriptiva, sustantiva y simbólica, en este último aspecto es posible disentir; según el curso de la explicación y planteo de otras autoras (Pitkin, 1985; Franceschet y Piscopo, 2008; Caminotti, 2013), lo que en el libro se plantea como tipo de representación simbólica no es un tipo sino un carácter que puede adquirir la representación descriptiva y sustantiva.

Hasta la obtención del sufragio, las mujeres tienen, lo que en la obra se denomina, "ciudadanía partida". Mantienen un papel doméstico, secundario y subsumido a las voluntades masculinas y blancas. Sin embargo en Brasil, a ochenta años de la legalización de su participación política, y a pesar de mecanismos como las cuotas de género, no se ha modificado el predominio político de los hombres. Para el período 2015-2019, tras veinticuatro años de aplicación de las cuotas, las cámaras legislativas siguen siendo terreno de hombres, viejos, blancos y heterosexuales y las bancas ocupadas por mujeres no llegan a representar un cuarto del total en las Cámaras de Diputados y de Senadores (Altamirano y Mulet, 2019: 6-7). ${ }^{2}$

Las autoras proponen, para comenzar a repensar los espacios políticos, que la presencia y ocupación de cargos por parte de mujeres no implica la idea de una "política feminizada" en los términos en que la sociedad define la feminidad, sino una política más atenta a las necesidades de las mujeres. ${ }^{3}$. Sí definen las políticas públicas con perspectiva de género como aquellas que reconocen la desigualdad e implementan acciones diferenciadas dirigidas a las mujeres (Pereira de Melo y Thomé, 2018: 153), afirmando que los estudios desde esta perspectiva permiten evaluar si las acciones gubernamentales contribuyen o no a una sociedad más igualitaria.

En este libro, las autoras trazan una linealidad entre el aumento de la participación femenina, la perspectiva de género en las políticas públicas y la cantidad de demandas femeninas en la agenda política. Sobre esta cuestión, es necesario advertir que más mujeres en el espacio político no equivale a pensar más feministas en él, e incluso agendas políticas feminizadas no son equiparables a un aumento en las políticas públicas con perspectiva de género. Esta advertencia de ningún modo busca desmerecer las acciones en pos de aumentar la participación y abogar por una mayor representatividad del colectivo de mujeres, sino que es un llamado a pensar formas que aseguren

\footnotetext{
2 Respecto de esto, las autoras plantean que es un desafío modificar los efectos de las cuotas en el sistema electoral. Sin embargo, es necesario comprender la incompatibilidad de las leyes de cuota con el sistema político brasilero en general y el sistemas electoral de listas cerradas no bloqueadas en particular, siendo la clave la innovación de Ixs brasilerxs para aplicar distintos mecanismos e incentivos en la participación y elección de candidatas mujeres (Altamirano y Mulet, 2019: 6-7).

3 Para ahondar más en el fenómeno de la participación política de las mujeres son más que interesantes las ideas de pacto y de sororidad planteadas por Lagarde y de los Rios (2006).
} 
también la presencia del feminismo en el ámbito institucional.

En este sentido, la presidencia de Dilma Rouseff y la paupérrima interrupción de su mandato, en el caso brasilero, se muestran como un buen ejemplo de que a pesar de su importancia simbólica, no hay una subversión completa del orden establecido por la mera ocupación del cargo. Aun así, es compartida la visión de las autoras de que el período de gobiernos petistas fue el mejor en lo que se refiere a políticas públicas en perspectiva de género; la creación de la Secretaria de Políticas para as Mulheres, acompañada por la creación de la Secretaria de Promoção da Igualdade Racial, son claros ejemplos.

El libro que abordamos como bien indica su título, Mulheres y Poder, se aboca a indagar un binomio muy conocido dentro del feminismo, pero poco explorado e infravalorado muchas veces por el resto de la academia. La crítica de las autoras a la construcción del conocimiento científico debe ser sin dudas un aliento para quienes buscamos participar del mundo académico desde una perspectiva feminista. Es importante comprender que ese mismo título además genera un marco metodológico desde el que se aborda toda la obra, que versa sobre las mujeres y, en esa decisión, se deja afuera gran parte de la diversidad que presenta el feminismo como enfoque científico, como filosofía y como práctica. Repensar y reconstruir las relaciones políticas, sociales y económicas en clave no binaria es un desafío para viejxs y nuevxs investigadorxs.

Respecto del recorrido histórico y teórico de las diversas aristas sociales que atraviesan la vida de las mujeres en Brasil y en el mundo, la metáfora usada es contundente: las mujeres fueron apagadas. Para ello Pereira de Melo y Thomé toman la decisión de nombrar a muchísimas mujeres, sobre todo brasileras, poco conocidas, con trayectorias realmente significativas, algo que no debe hacernos olvidar a Ixs lectorxs las luchas colectivas detrás de esos ejemplos individuales. Aun así, con esa metáfora, las autoras reafirman la necesidad de accionar para reivindicar y ayudar a las mujeres a autoafirmarse como actrices de los procesos históricos y sociales, algo que no se puede lograr sin traccionar desde el poder institucional.

\section{Q Referencias bibliográficas}

»Altamirano, J. y Mulet, J. (2019). Cuota de género y sistemas electorales: Argentina y Brasil en perspectiva comparada. En Descentrada, 3(2), eog2. En línea: https://doi.org/10.24215/25457284eo92.

»Butler, J. (2017). El género en disputa: el feminismo y la subversión de la identidad. Buenos Aires, Paidós.

"Caminotti, M. (2013). La representación política de las mujeres en el período democrático. En Revista SAAP. 7 (2). San Martín, Universidad Nacional de San Martín, pp. 329-337.

"De Beauvoir, S. (2016). El segundo sexo. Buenos Aires. Debolsillo.

"Franceschet, S. y Piscopo, J. (2008). Gender Quotas and Women's Substantive Representation: Lessons from Argentina. En Politics \& Gender (4), pp. 393-425.

"Lagarde y de los Ríos, M. (2006). Pacto entre Mujeres. Sororidad. España, Coordinadora Española para el Lobby Europeo de Mujeres (CELEM), Departamento de Comunicación.

»Pitkin, H. F. (1985). El concepto de representación. Madrid, Centro de Estudios Constitucionales.

"Scott, J. (1990). El género: una categoría útil para el análisis histórico. En Nash, M. y Amelang, J. (eds). Historia y género: las mujeres en la Europa moderna y contemporánea, pp. 23-56. Valencia, Alfons el Magnanim. 